\title{
вмJ Global Health Intended and unintended effects: community perspectives on a performance-based financing programme in Malawi
}

\author{
Chisomo Petross, ${ }^{1,2}$ Shannon McMahon, ${ }^{2}$ Julia Lohmann, ${ }^{2,3}$ Rachel P Chase, ${ }^{2}$ \\ Adamson S. Muula, ${ }^{4,5}$ Manuela De Allegri ${ }^{2}$
}

To cite: Petross C, McMahon S, Lohmann J, et al. Intended and unintended effects: community perspectives on a performancebased financing programme in Malawi. BMJ Global Health 2020;5:e001894. doi:10.1136/ bmjgh-2019-001894

Handling editor Seye Abimbola

- Additional material is published online only. To view please visit the journal online (http://dx.doi.org/10.1136/ bmjgh-2019-001894).

CP and SM contributed equally.

Received 6 August 2019

Revised 20 January 2020

Accepted 27 January 2020
Check for updates

(c) Author(s) (or their employer(s)) 2020. Re-use permitted under CC BY-NC. No commercial re-use. See rights and permissions. Published by BMJ.

For numbered affiliations see end of article.

Correspondence to Ms Chisomo Petross; petrosschisomo@gmail.com

\section{ABSTRACT}

Background Several performance-based financing (PBF) evaluations have been undertaken in low-income countries, yet few have examined community perspectives of care amid PBF programme implementation. We assessed community members' perspectives of Support for Service Delivery Integration - Performance-Based Incentives ('SSDI-PBI'), a PBF intervention in Malawi, and explored some of the unintended effects that emerged amid implementation. Methods We conducted 30 focus group discussions: 17 with community leaders and 13 with mothers within catchment areas of SSDI-PBI implementing facilities. We analysed data using the framework approach.

Results Community leaders and women had mixed impressions regarding the effect of SSDI-PBI on service delivery in facilities. They highlighted several improvements (including improved dialogue between staff and community, and cleaner, better-equipped facilities with enhanced privacy), but also persisting challenges (including inadequate and overworked staff, overcrowded facilities and long distances to facilities) related to services in SSDI-PBI-implementing facilities. Further, respondents described how four targeted service indicators related to maternal risk factor management, antenatal care (ANC) in the first trimester, skilled birth attendance and couple's HIV testing sparked unintended negative effects as experienced by women and communities. The unintended effects included women returning home for delivery, women feeling uncertain about their pregnancy status, women feeling betrayed or frustrated by the quality of care provided and partnerless women being denied ANC.

Conclusion PBF programmes such as SSDI-PBI may improve some aspects of service delivery. However, to achieve system improvement, not only should necessary tools (such as medicines, equipment and human resources) be in place, but also programme priorities must be congruent with cultural expectations. Finally, facilities must be better supported to expect and then address increases in client load and heightened expectations in relation to services.

\section{BACKGROUND}

Malawi has made considerable progress in improving health in recent decades, yet

\section{Key questions}

What is already known?

- There is mixed evidence on the impact of performance-based financing (PBF) programmes on health service utilisation and quality of care.

- Little is known on how communities experience care under PBF.

- Limited literature available indicates the emergence of unintended consequences concerning healthcare delivery under PBF.

What are the new findings?

- Beyond positive impacts on service delivery, unintended negative effects may emerge due to implementation realities and can affect community experiences of care.

- PBF ability to produce change is constrained by health system factors which affect the implementation reality.

What do the new findings imply?

- Health system factors and the socio-cultural elements should be taken into consideration when implementing PBF programmes.

- Facilities must receive additional structural and human resource support to address both increased service load and enhanced expectations on quality of care induced by PBF.

challenges particularly related to maternal health remain. The country is among the most dangerous places in the world to become a mother; ${ }^{1}$ one in 34 Malawian women will die due to maternal causes in her lifetime. ${ }^{23}$ Several programmes and policies unveiled in recent years both within Malawi and globally have sought to address maternal health. An intervention that has garnered considerable attention is 'performance-based financing' (PBF).

$\mathrm{PBF}$ is a health system intervention that provides incentives (monetary or tangible) to 
health facilities 'for delivering specific services, provided the services follow explicit protocols, with a system of inspection and auditing to assure compliance'. ${ }^{4}$ Under PBF, the health service purchaser (such as a Ministry of Health or implementing body) works with health administrators and providers to devise performance contracts, which define both the performance indicators to be achieved and the manner to reward their achievement. ${ }^{5}$ Further key PBF elements aimed at supporting facilities in improving performance include increased management autonomy at the level of the single facilities and intensified service delivery monitoring and supervision by both health system and community stakeholders. ${ }^{67}$

Evidence from PBF programmes across low- and middle-income countries is mixed in regard to its impact on service utilisation and quality. ${ }^{89} \mathrm{PBF}$ has been observed to yield a positive effect on maternal care services in Rwanda, ${ }^{10}$ Burundi ${ }^{11}$ and Tanzania, ${ }^{12}$ but not in Afghanistan; ${ }^{13}$ a positive effect on childhood immunisations in Cameroon ${ }^{14}$ but not in Rwanda, ${ }^{10}$ Afghanistan $^{13}$ or Burkina Faso; ${ }^{15}$ and mixed effects on various indicators of quality of care. ${ }^{9}$ Incentives have also been associated with drawbacks such as gaming by providers to maximise results ${ }^{16}$ and perceptions of unfairness among providers in rewarding performance that negatively affects delivery of quality of care to clients. ${ }^{17-21}$

Although an increasing number of studies have explored quality of care within PBF, most of these are quantitative studies. ${ }^{10-1322}$ Qualitative studies have primarily explored insights from providers. ${ }^{23-25}$ Literature on PBF experiences by community members and healthcare clients is rare. ${ }^{24}$ 26-29 This is despite evidence of some unintended outcomes regarding provider behaviour towards clients. ${ }^{2024}$ For instance, in an evaluation of another PBF programme in Malawi, women reported improvements in certain aspects of quality of care, but also continued incidences of disrespectful care in spite of the fact that the PBF intervention was coupled with conditional cash transfers to support women delivering at selected health facility. ${ }^{27}$ An evaluation in Tanzania found that providers developed strategies to reach targets that could be harmful to clients. ${ }^{30}$ They threatened to fine women, and to deny their children immunisations and health records if women did not deliver in a health facility. ${ }^{23}$ Studies in Rwanda and Malawi found that health workers documented the care provided retrospectively in order to fulfil a target of 'completed forms' which was required to receive incentives. ${ }^{1621}$

The main objective of this study is to explore collective perceptions of care by community members-including both clients and community leaders-during the implementation of the Support for Service Delivery Integration - Performance-Based Incentives (SSDI-PBI) programme in Malawi, a particular PBF programme which did not tie performance incentives to individual health worker gains. Sub-objectives included exploring community and clients' perspectives on the improvements produced by the programme and remaining challenges. While not initially an aim of the study, we also highlight some of the unintended programme effects revealed by clients. Not only is an exploration of service users' experiences valuable in understanding how $\mathrm{PBF}$ affects maternal care provision and use, but capturing clients' perspectives is crucial to guide recommendations regarding whether and how to modify health programs in the event of scale-up.

\section{METHODS \\ Study setting}

Malawi is a low-income country with an economy largely dependent on agriculture, and a health system largely dependent on foreign aid. ${ }^{31}$ One quarter of the country's estimated 17.5 million citizens live in extreme poverty. ${ }^{31}$ Health institutions are either governmentowned or faith-based organisations, with only a minority being managed by for-profit private institutions. ${ }^{32}$ Across all districts, implementation of health interventions is guided by the health sector strategic plan, which emphasises improving service coverage via an essential healthcare package (EHP) ${ }^{32}$ The EHP states a stipulated set of health services covering the most common conditions be delivered free of charge at point-of-use in public facilities and in private facilities contracted via service-level agreements. ${ }^{32}$ Utilisation of healthcare services is relatively high, but EHP services are often inadequately provided ${ }^{33}$ due to a shortage of human resources, poor infrastructure, lack of medical equipment and supplies and inadequate financing. ${ }^{34}$ This situation has resulted in slow progress towards reduction of morbidity and mortality in the country. ${ }^{35}$

In trying to address these challenges, the government of Malawi explored PBF as a means to improve access to health services of high quality. The country recently concluded the implementation of two PBF-specific programs entitled 'Results Based Financing for Maternal and Neonatal Health' (RBF4MNH) ${ }^{36}$ and 'Support for Service Delivery Integration - Performance-Based Incentives' (SSDI-PBI).$^{37}$ The focus of this paper is the latter programme, SSDI-PBI, implemented in 17 facilities across three districts: Mangochi, Nkhotakota and Chitipa.

\section{The intervention}

The SSDI-PBI programme and its implementation processes have been described in detail elsewhere. ${ }^{37}$ The programme, which lasted 2 years, was introduced in 2014 into a context where: funding for health resources was largely input based; financial autonomy was held at district and higher organisational levels (with health facilities holding limited control over their own resources); accountability of health facilities to the health system or communities was largely informal and inconsistent and severe general shortages in human and material resources persist. ${ }^{33} 38$ SSDI-PBI is similar to other PBF programs in that rewards were provided to health facilities on provision of a predefined set of health services stipulated in 
a service contract. In SSDI-PBI, improved service provision aimed to increase utilisation rates (also called 'quantity indicators' (online supplementary file appendix 2)) across the maternal health continuum (during antenatal, delivery and postpartum periods), newborn and child health and HIV and AIDS care and treatment. Quality indicators emphasised improvements in both the facility environment (eg, clean rooms that offered privacy) and how care was provided (eg, medical equipment was available and functioning), see online supplementary file appendix 2. In addition, the programme relied on an explicit community assessment of quality of service provision (via community meetings defined as 'community scorecards' and exit interviews). Payouts to facilities were made based on the joint assessment of quantity indicators, quality indicators and the community scores.

The specific focus of this qualitative study on maternal care arises from the fact that while SSDI-PBI did not exclusively address maternal care services, the intervention aimed to improve maternal health by increasing the quantity (service coverage rates) and quality of: antenatal care visits within the first trimester, births attended by a skilled birth attendant (a doctor, nurse or midwife), postnatal care within 7 days of delivery and patients counselled for family planning.

The SSDI-PBI programme was different from many other PBF programs in at least two respects: (1) the programme did not provide any monetary incentives (in the form of salary bonuses) to individual health workers; and (2) the programme's incentives were exclusively goods-based, with the implementing agency coordinating the procurement and distribution of supplies and equipment to facilities in line with targets and incentives set in the facility business plan. ${ }^{39}$

\section{Study design}

This qualitative study was embedded within a broader mixed-methods evaluation of SSDI-PBI ${ }^{37}$ Since our study aimed to explore group perceptions and experiences of SSDI-PBI, we employed qualitative methods. ${ }^{40}$ Because the team was interested in social norms, conversational interactions and bringing to the surface perspectives of the community in relation to healthcare amid SSDI-PBI, focus group discussions (FGDs) were used.

\section{Data collection}

Data collectors were trained for 5 days (including pilot testing). Data collectors had previous experience collecting data to inform health interventions, and they had academic training in nursing, journalism, midwifery, social work, education, administration or medicine. The qualitative training emphasised the SSDI-PBI intervention, FGD techniques and ethics. In March 2016, we conducted 17 focus group discussions with 4 to 12 community leaders per FGD across the 17 facility catchment areas (one FGD per facility). We also conducted 13 FGDs with 5 to 10 mothers in the catchment areas of 13 facilities (FGDs were concluded on saturation of themes). Community health workers (including health surveillance assistants and volunteers) assisted in identifying participants. In addition, data collectors canvassed villages and invited those present (and eligible) to participate. Sampling was purposively focussed on gathering perspectives from those living in the catchment areas of SSDI-PBI implementing facilities who were either mothers or community leaders (village health committee members, ward councillors, chiefs, village headmen, religious leaders and traditional healers). Topics across FGDs covered impressions of facilities, changes in facilities over time and knowledge and perceptions of the SSDI-PBI programme.

Techniques undertaken to collect trustworthy, high quality data followed the approach of naturalistic inquiry put forth by Lincoln and Guba (1985), ${ }^{42}$ including prolonged engagement, triangulation and reflexive dialogue (see table 1). Following each FGD, a lead researcher debriefed data collectors for information regarding emergent themes, reflexive insights and questions that could merit more deliberate follow-up in later FGDs. ${ }^{43}$ During these meetings, the research team spoke openly about their thoughts and perceptions of the programme (both positive and negative) in order to build reflexive memos that were used to further inform the conduct of later interviews and, ultimately, the coding process. Notes captured during these debriefings were also shared with the wider research team (including senior authors) and formed the basis for coding all FGDs. All FGDs were conducted in the local language (Chichewa), recorded, transcribed, translated into English and quality controlled by bilingual research assistants. FGD tools are included in online supplementary file appendix 1 .

\section{Data analysis}

The first and second author analysed the data with support from all co-authors, drawing on the framework approach outlined by Pope. ${ }^{44}$ An inductive approach was used, ${ }^{40}$ meaning that themes were mainly generated from the data that were collected. First, the lead author repeatedly read transcripts and reviewed notes in order to gain familiarity with the data and understand connections across concepts. ${ }^{45}$ Second, the first author noted emerging themes from the text and coded chunks of data representing themes. ${ }^{45}$ Third, the first and second authors explored thematic areas by displaying the relevant coded text in each category to identify key themes and inter-relationships. Finally, all co-authors interpreted findings by discussing and agreeing on key themes that addressed the research question. The process was conducted using NVivo software.

\section{Ethical considerations}

Respondents were informed in writing and orally about the nature and scope of the study. Participation in the study was entirely voluntary. Informed consent was sought from all study respondents. Respondents signed or finger printed the consent forms to show that they understood 
Table 1 Techniques to enhance the credibility and confirmability of this qualitative study as informed by Lincoln and Guba's criteria $^{42}$

\begin{tabular}{|c|c|}
\hline Principle & Execution of the principle in this study \\
\hline $\begin{array}{l}\text { (1) Prolonged } \\
\text { engagement (scope) }\end{array}$ & $\begin{array}{l}\text { The research team is either originally from or has lived and worked in this setting over several years. The research team } \\
\text { was attuned to the priorities, social dynamics and contextual factors pertinent to this study setting. }\end{array}$ \\
\hline $\begin{array}{l}\text { (2) Persistent observation } \\
\text { (depth) }\end{array}$ & $\begin{array}{l}\text { The research team has been involved in multiple data collection activities pertinent to this project for a period of several } \\
\text { months, with data collection for this specific substudy stretching over } 2 \text { months. The research team was attuned to tools, } \\
\text { behaviours and relationships related to this issue in the study setting. }\end{array}$ \\
\hline (3) Peer debriefing & $\begin{array}{l}\text { Debriefings }{ }^{43} \text { were conducted each evening throughout data collection and involved all members of the data collection } \\
\text { team, sharing, questioning and comparing one another's findings. }\end{array}$ \\
\hline $\begin{array}{l}\text { (4) Source triangulation } \\
\text { (multiple data sources) }\end{array}$ & $\begin{array}{l}\text { The team collected data from multiple types of stakeholders and using diverse data collection tools across multiple } \\
\text { settings. }\end{array}$ \\
\hline $\begin{array}{l}\text { (5) Analytical } \\
\text { triangulation (multiple } \\
\text { data analysts) }\end{array}$ & $\begin{array}{l}\text { Memos drawn up during peer debriefings informed the development of a codebook. } \\
\text { Members of the research team who undertook data collection also participated in data analysis. } \\
\text { All final results were reviewed and discussed by the full research team. }\end{array}$ \\
\hline (6) Audit trail & Memos drawn up during peer debriefings formed the basis for an audit trail of the study. \\
\hline (7) Reflexivity & $\begin{array}{l}\text { Within the research team, those with extensive experience (as scientists or practitioners who are from the study setting, } \\
\text { or have worked for years in the study setting) provided contextual insight. The research team encouraged one another to } \\
\text { explicitly consider the lens through which they viewed the data, and how this lens affected the focus group discussion } \\
\text { encounter (in terms of questions, probes and perceptions). These conversations were typed up during debriefings. }\end{array}$ \\
\hline
\end{tabular}

the conditions of the study and had agreed to take part. Further, respondents were informed to be free to stop any time if they felt it was important for them to do so. It was also made explicit to them that doing so will not disadvantage them in any way.

\section{Patient and public involvement}

Neither patients nor the public were involved in the design, conduct, reporting or dissemination of our research.

\section{RESULTS}

Tables 2 and 3 show key respondent characteristics. Leader focus groups consisted of between 4 to 12 predominantly male participants, with group composition ranging from all male to $60 \%$ female, most of whom took part in their role as traditional authority, health centre advisory committee member or religious authority. Women's focus groups ranged from 5 to 10 respondents and were well balanced in regards to age, parity and pregnancy at the time of the FGD.

We first present an overview of the experiences and perceptions of women and community leaders in accessing maternal services in the context of SSDI-PBI. We present results distinguishing between areas of services delivery where woman perceived notable improvements, areas where pre-existing challenges persisted and areas where new challenges (unintended consequences) of the SSDI-PBI intervention emerged. We then outline the processes by which well-intended service goals lead to unintended effects.

In terms of improvements and challenges, community leaders and women had mixed impressions regarding the SSDI-PBI programme's effect on facilities (see table 4). They highlighted several improvements, but also noted persisting challenges related to services received from SSDI-PBI health facilities. Community leaders were generally more conversant on the programme, attributing changes explicitly to the SSDI-PBI programme. Women were less conversant on the programme, but could speak at length about changes observed within facilities in the preceding year (which aligned with the onset

\begin{tabular}{|c|c|c|}
\hline & $\mathbf{n}$ & $\%$ \\
\hline Total & 123 & $100 \%$ \\
\hline \multicolumn{3}{|l|}{ District } \\
\hline Chitipa (3 FGDs) & 24 & $20 \%$ \\
\hline Mangochi (7 FGDs)* & 43 & $35 \%$ \\
\hline Nkhotakota (6 FGDs) & 56 & $45 \%$ \\
\hline \multicolumn{3}{|l|}{ Sex } \\
\hline Female & 26 & $21 \%$ \\
\hline Male & 97 & $79 \%$ \\
\hline \multicolumn{3}{|l|}{ Age } \\
\hline$<30$ & 8 & $7 \%$ \\
\hline $30-45$ & 47 & $38 \%$ \\
\hline $46-60$ & 53 & $43 \%$ \\
\hline$>60$ & 14 & $11 \%$ \\
\hline Don't Know & 1 & $1 \%$ \\
\hline Role & & \\
\hline
\end{tabular}

\begin{tabular}{lll} 
Traditional authority & 46 & $38 \%$ \\
\hline Health advisory committee & 37 & $30 \%$ \\
Religious leader & 15 & $12 \%$ \\
\hline Other & 25 & $20 \%$ \\
\hline
\end{tabular}

*Number and respondents' characteristics not available for one FGD conducted in Mangochi, due to field failure in recording the relevant information. Therefore, the table shows information for seven instead of eight FGDs for Mangochi.

FGD, focus group discussion. 
Table 3 Characterists of participants in women's' FGDs

\begin{tabular}{lcc}
\hline & $\mathbf{n}$ & $\%$ \\
\hline Total & 90 & $100 \%$ \\
\hline District & & \\
$\quad$ Chitipa (1 FGD) & 8 & $9 \%$ \\
\hline Mangochi (6 FGDs) & 55 & $61 \%$ \\
\hline Nkhotakota (5 FGDs) & 27 & $30 \%$ \\
\hline Age & & \\
\hline$<18$ & 9 & $10 \%$ \\
\hline $18-25$ & 52 & $58 \%$ \\
\hline $26-35$ & 24 & $27 \%$ \\
\hline$>35$ & 4 & $4 \%$ \\
Don't Know & 1 & $1 \%$ \\
\hline Parity & & \\
\hline 0 & 19 & $21 \%$ \\
\hline 1 & 15 & $17 \%$ \\
\hline 2 & 23 & $26 \%$ \\
\hline 3 & 19 & $21 \%$ \\
\hline $4+$ & 13 & $14 \%$ \\
\hline Pnknown & 1 & $1 \%$ \\
\hline Yes & & \\
\hline Don't Know & 33 & $37 \%$ \\
\hline & & \\
\hline & & \\
\hline
\end{tabular}

*Number and respondents' characteristics not available for one FGD conducted in Mangochi, due to field failure in recording the relevant information. Therefore, the table shows information for six instead of seven FGDs for Mangochi.

FGD, focus group discussion.

of SSDI-PBI). Stark or notable differences in perspectives did not emerge when comparing across facilities.

\section{Notable improvements}

The most fundamental improvement described by both respondent types involved the appearance of facilities. Both women and leaders described how facilities looked better; they were cleaner, more inviting, had more equipment, better landscaping, better fencing, bright curtains and (importantly for women) facilities began providing forms of privacy (such as screens) during childbirth. Across respondent groups-though not uniformly in catchment areas across facilities-respondents described a sense that facilities had a more consistent supply of drugs (several women mentioned iron tablets and Panadol), that providers were 'better dressed' and 'doing more' to reach clients living both near and far from facilities (particularly via 'outreach clinics'), and that providers began to more heavily emphasise that women's partners should be engaged in the care seeking process. Finally, community leaders in particular described how community-facility dialogue meetings provided a forum for clients to openly air 'grievances' and express their concerns to facility-based providers on topics such as client-provider interactions and opening hours. This was described as an awkward, sometimes combative endeavour, but was viewed as ultimately beneficial among leaders as it compelled providers to feel more beholden to the communities they serve and, as one leader said, 'to view us as people'. Leaders also mentioned that via discussions with providers, they learnt that they had a responsibility, as leaders, to advocate for the intervention; leaders described taking providers' messages to heart and thus encouraging men to accompany women to facilities, and encouraging women to visit facilities earlier in pregnancy, and to give birth in facilities. FGDs with women triangulated these findings.

\section{Persistent challenges}

The most fundamental persisting challenge described by both respondent types involved a sense that providers were 'overworked', 'unhappy', 'bitter' or 'under stress'. Respondents were careful to note that there was not a negative change per se, as providers were not previously happy or stress-free. But since the onset of SSDI-PBI, respondents felt that providers had more demands placed on them without necessarily receiving additional human resource support. SSDI-PBI exacerbated preexisting shortfalls, particularly when the programme was in its earliest stages. Other persistent challenges related to factors that respondents had thought would change (or should change) in tandem with the aforementioned improvements. For instance, respondents noted that there was outreach to attract more women to attend facilities earlier in pregnancy (this was viewed as an improvement); however, this outreach-and the earlier care-seeking it compelled-were not accompanied with improvements in availability of pregnancy test kits which meant that women saw no purpose in seeking care earlier. Women and leaders also highlighted that facilities remained overcrowded (a situation viewed as heightened amid PBI), that recently-delivered mothers were forced to share beds (a situation described as preceding PBI, but also exacerbated by it) and that many challenges related to distance such as pregnant and labouring women travelling far to reach facilities were not overcome. In contrast to what clients perceived in some facilities where drug supplies appeared to have improved, other facilities appeared to have exacerbated drug shortages.

\section{How unintended effects can exacerbate challenges}

Across the SSDI-PBI facility catchment areas, respondents described their experiences of maternal and child healthcare in a manner that underscored how complexities are likely to arise when a programme is implemented in a setting that lacks necessary resources (such as medicines, equipment or health personnel) or when the priorities of the programme do not dovetail with the values, norms or preferences of the community (such as setting targets that collided with local gender norms). Four targeted service indicators were described 
Table 4 Client and community leader perspectives on improvements and challenges amid SSDI-PBI

\section{Perceptions of facilities \\ Improvements}

Facility looks nicer (curtains, cleanliness)

Facility has improved infrastructure (clean toilets, inhouse labs, dedicated maternity "Just look at those new toilets. So clean!" - FGD mothers, facility 7 wings)

More community outreach/ engagement by providers with community directly and with health advisory committees, clinics

More equipment and materials (blood pressure machines, motorcycles, uniforms, computers, bed nets, lawnmowers)

Distribution of items (mosquito nets) to pregnant mothers

More reliable operating hours

Providers 'forced' to be nicer to clients

\section{Community leader and client quotes}

\section{Women feel more comfortable and welcome in facility spaces.} giving birth. because they own the facility" - FGD leaders, facility 2 care when they are pregnant" - FGD leaders, facility 9

$\mathrm{PBI}$ facilities seem to have more Impression of enha to seek services (ANC, HIV, maternal health programs generally) of drug stocks for long." - FGD leaders, facility 11 compared with the past." - FGD leaders, facility 12 river to wash. We can wash here." - FGD mothers, facility 17 facility 10 and via antenatal care outreach

"The place is just clean. Cleaner than before... Yes, we are very happy with the changes because we have now things happening which were not happening like our hospital is now well taken care of-for instance the painting it has been a long time since they had last painted the walls." - FGD mothers, facility 17

Women have greater confidence that the facility is prepared to provide care, and they enjoy privacy while

Community leaders appreciate having a better-defined role in promoting access to care in their communities; Women welcome information that helps them seek care in a timely and effective fashion.

"In the past community would not have ownership and were thinking that the facility is for government and there were not caring for it. After civic education, community is now aware that the facility belongs to them.

When the chiefs or politicians ask them (community members) to do something like moulding bricks they do

"... many things have been implemented. In the communities, there are committees that are working with chiefs ... indeed there are women who are working in communities to enhance women to start antenatal

"... outreach clinicians came to me after my child was born and educated me on antenatal care and its advantages... They encouraged us to go for regular check-ups ... so that we prevent complications ... so that we save our lives and the lives of our children." - FGD mothers, facility 10

"...The drug consignments are coming in good intervals, so it's like here at facility 11 we are not running out

"Through this PBI programme more children are being vaccinated to reach the target, and there is more outreach being done compared in the past, and women are encouraged to be delivering at the facility, so we also did something on this that when a pregnant woman visits ANC, she receives a basin and those who have delivered at the facility receive a piece of cloth (chitenje). So this is all done because of the PBI programme, which is making us work so hard in order to win more money at our facility! As the result the population of families coming to this facility has greatly increased most especially pregnant women

"PBI has taught us a lot. Our families are now going to the health facility together as a family for HIV testing and also encouraged to avoid maternal death." - FGD leaders, facility 13

"Of course ... we like these changes... Yes, when you deliver at the postnatal ward, now there are mattresses, so at least we are sleeping on mattresses." - FGD mothers, facility 11

"This year has brought good things like water. We are happy about it because... we don't have to go to the

"In just this past year, they've really been telling us about mosquitoes, giving us nets after we deliver our babies (women nod heads in agreement, smiling)" - FGD mothers, facility 13

"In the past years, the health providers would only attend to those clients who would come in the morning hours only, all those who came after lunch would be sent back and told to come the following morning but now these years, even a client who comes after lunch, they are attended to." - FGD leaders, facility 5 "...even the way the services are being provided at the facility, the services are now being provided in good time, even if there may be a huge number of clients, but they are being attended to in time." - FGD leaders,

"These days, it's like they want to help us very well unlike before where people used to complain a lot, and providers would take their time in attending to us... They are now listening to us and when they have the medicines they give them faithfully... This is very, very welcome for us." - FGD mothers, facility 8 "We are very happy because the providers treat us well now." - FGD mothers, facility 15

"It's since $2015 \ldots$... (the nurses) have been receiving us so nicely, explaining things so nicely, welcoming us with openness" - FGD mothers, facility 1

\section{Challenges unchanged}

Chronic drug and supply shortages-pregnancy test kits not available during early ANC iron tablets often out of stock, essential items not available in-house during delivery

"So when we are going to deliver our babies, we still even now we need to carry our own razor blades, candle, plastic papers, threads. We are always told not to forget these things." - FGD mothers, facility 8 "...there are no drugs - when you are sick and you go for treatment you are told that there are no drugs. When our children are sick of malaria and we go to seek for medical attention we are being told that they are no drugs for malaria and we are stranded when we are told like that and they give us a prescription so that we go and buy from a private hospital, and we are saying that if we came to this hospital it means that we cannot afford the private hospital!" - FGD mothers, facility 4

"...because the big hospital is the (District 3 ) district hospital, which is far from here ... sometimes a pregnant woman may start bleeding and call the ambulance ...(but) it's not here, it's ... somewhere else." FGD community leaders, facility 13 


\begin{tabular}{l}
\hline Perceptions of facilities Community leader and client quotes \\
Challenges created or exacerbated
\end{tabular}

Challenges created or exacerbated

Men being encouraged to accompany women for services; to be attentive to women's health issues/ messages

Inadequate staffing, overworked/ tired/ stressed providers

Overcrowding in facilities and inadequate facilities (especially labour wards)

"The problem is... men are not interested. They are not interested in family planning they want women bearing children now and again... Men are not accepting to come with their wives... to have their wives on family planning." - FGD mothers, facility 1

"Why can't the doctor talk to our men directly? Teach our men directly." - FGD mothers, facility 8

Women sympathise with some staff who have problems delivering quality care under greater pressure, but are reticent to return to facilities/ providers who resort to disrespectful care when under such stress "As you understand that each person has time to rest so this is also causing the health worker to be harsh when attending patients because of tiredness. For instance, being the only health worker at the facility is a problem ... same person work the whole day without resting but during night is also called to attend to a patient. Sometimes the health worker tell us not to call him for assistance because he is tired wants to sleep" - FGD Leaders, facility 16

"Sometimes, they just have no more patience. And then they just, they shout at us." - FGD mothers, facility 13

"We deliver (in the facility) because if we deliver at home we are charged a fine. We are scared to pay the fine. But when we delivery here, we are ignored and we suffer." - FGD mothers, facility 11

"Most of the times the nurses do not respond to our call immediately and we are not closely monitored and assisted but we know that during this time its when we need the nurse most because anything can happen even complications may arise. Most of the times we received insults for only asking for their help so we are very concerned because of the treatment we are receiving at District 2 District Hospital especially in maternity has resulted in some mothers and babies dying." - FGD mothers, facility 4

"...this baby (points to 1-month-old), I delivered at the hospital but instead of them welcoming me they were busy with their phones and when I tried to call the nurses they were just shouting at me ... we are begging then to have mercy on us. " - FGD mothers, facility 4

Women shared beds with other maternity clients after delivery. Clients screened for HIV did not have a private space for consultations. Waiting times were longer.

"The biggest problem is the labour ward. It is still small, and we heard that the maternity section will be extended but up to now nothing has been done, and the problems of space are still there. There are some women are delivering on the floor." - FGD mothers, facility 8

"Women are delivering their babies on the floor." - FGD mothers, facility 11

"... health workers are not enough... we usually wait for long hours before receiving care. Normally we wait from morning up to afternoon hours without assisted. This is because there is only one person who attends out patients." - FGD Leaders, facility 7

ANC, antenatal care; FGD, focus group discussion; PBI, performance based incentives; SSDI-PBI, Support for Service Delivery Integration -

Performance-Based Incentives.

as sparking unintended negative effects after they were introduced as part of SSDI-PBI. In figure 1, we highlight leaders' descriptions of four targeted services (column A), leaders' descriptions of how providers operationalised the services (column B), how the operationalisation of the target was received and/or perceived by communities (column $\mathrm{C}$ ) and the unintended consequence that eventually unfurled (column D). While figure 1 and this text emphasise negative unintended consequences, we note that clients viewed many positive effects of PBI (see table 1) yet positive consequences were viewed as both expected of and intended by the programme.

\section{Compelling home delivery}

The SSDI-PBI programme sought to increase the proportion of skilled attendance at birth and referral of highrisk pregnancies to higher-level facilities. Leaders and women reported that the importance of giving birth in facilities was reiterated to them in the course of the programme. Leaders described telling women that they must go to facilities; women confirmed that they had received such messages from leaders. Women and leaders described thinking that the care on offer would be notably improved because the SSDI-PBI programme placed such an emphasis on making sure care was sought in facilities. Leaders and women thus described disappointment with the level of crowding in facilities, and felt frustrated that issues of disrespectful maternity care such as feeling disregarded and/or talked down to by overworked or absentee providers during delivery were unchanged or in some cases perceived to have worsened.

Women who were identified as at-risk said they were now being referred to higher-level care, but were not afforded the means (whether funds for public or private transport, or access to a free-of-charge option such as an ambulance) to make a referral logistically or financially feasible. Although women were encouraged to save funds during pregnancy, this guidance felt hollow or out of touch in the context of poor crop yields, fuel shortages and generalised poverty. Leaders confirmed that referral, which they described as a message underscored in the programme, can be futile and dangerous as it could lead to births en route if families lack financial or logistical means to reach a facility or to sustain oneself once at a facility. 


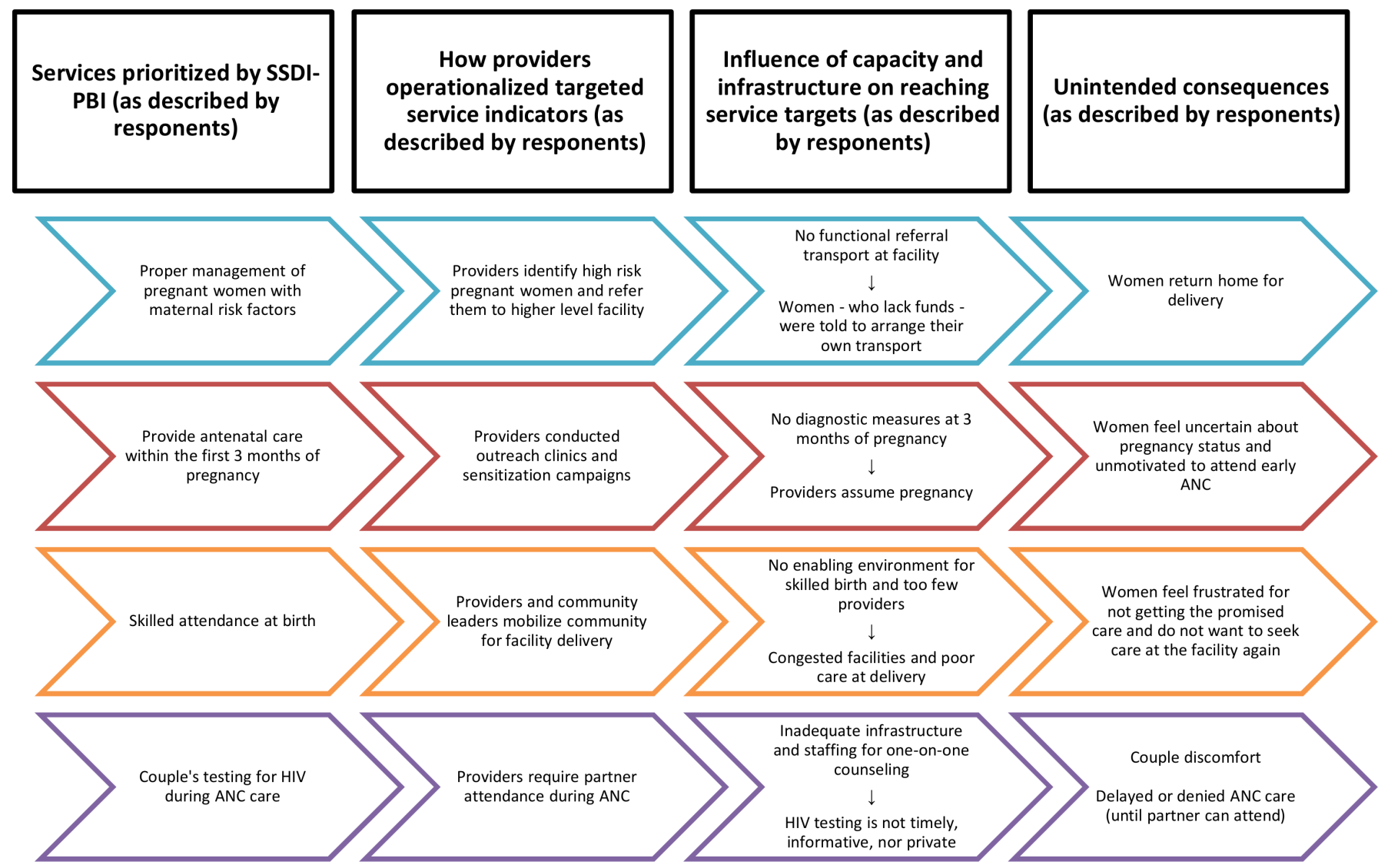

Figure 1 Unintended effects described by leaders amid SSDI-PBI. ANC, antenatal care; SSDI-PBI, Support for Service Delivery Integration-Performance-Based Incentives.

Several women and leaders expressed frustration; respondents felt that they were strongly encouraged to support delivery in facilities as a direct result of PBI but this encouragement was not accompanied with improvements that would make women feel safer during childbirth. Paradoxically, the insistence that women attend facilities for birth led to instances of reinforcing underlying aversions to facility delivery.

\section{Confusion among women regarding pregnancy}

The SSDI-PBI programme sought to increase the number of pregnant women starting antenatalcare (ANC) in the first trimester. Leaders and women described knowing that this was a priority of the programme due to key messaging during outreach clinics and other health communication campaigns, and a behaviour that needed to be modified in the context of the programme. Women then assumed that there was a purpose in attending facilities for earlier ANC; that more care would be provided and/or more tests would be done to determine the existence and health of a pregnancy. Women described attending facilities earlier in their pregnancies, but being disappointed to discover that they would not be given a pregnancy test, nor would they receive any additional care. Women said providers merely palpated their abdomen but could not confirm a pregnancy status and thus could not provide pregnancy-related care. This left many women disappointed, as they remained uncertain of whether they were pregnant and they felt the time and energy required to forgo other activities in favour of seeking ANC was in vain. As one woman, age 24, from Facility 5 said, "They couldn't tell me anything! They couldn't even tell me how many months my pregnancy was". The experience led several families to feel less certain about whether they were pregnant (since providers could neither confirm nor refute a pregnancy status); women also felt unsure of how their pregnancy may be progressing since no additional tests were conducted until a woman's status could be definitively (visibly) confirmed. This study was not designed to evaluate whether there was a quantifiable decline in the proportion of women given adequate care when presenting to the health facility. Deficiencies in care provision are likely to have existed before and persisted through PBF implementation. Women's reports suggest that SSDI-PBI sensitised communities to the issue, thereby sparking disappointment, irrespective of changes or lack thereof in actual quality of care.

\section{Burdens, delays and familial discord}

The SSDI-PBI programme sought to increase couples testing for HIV. Leaders and women did not describe being knowledgeable about this priority specifically, but they were aware of an increased insistence on having men accompany their partners to facilities during pregnancy (whereupon HIV tests were advised and routinely administered). Several leaders described being co-opted 
by facility-based staff to enforce a community-wide mandate that all pregnant women must attend ANC with their partners. Women concurred with this; they described how care was delayed or denied (particularly during early ANC visits) if they did not have an accompanying partner. The situation of needing a partner at ANC visits placed several women in a dilemma. A man could refuse to accept or publicly recognise paternity, or he may be constantly travelling and thus unavailable for health-related appointments. As one woman, age 30, from Facility 5 said, "I started going to antenatal at 5 months ...it would be possible to go at 3 months, but I failed because my husband was in South Africa. ... I waited for my husband to be back from the trip, because if I went on my own I could have been sent back".

Alternately, a woman may prefer not to disclose the identity of her unborn baby's father. In more mundane scenarios, boyfriends, partners or husbands could simply refuse to attend ANC, arguing that they feel unwelcome at health facilities or that their time is better spent earning money for their families. Women who struggled to get a partner to attend described delaying their first ANC visit and ultimately attending ANC alone (whereupon they were afraid of being scolded for not bringing a partner). In instances when men did accompany women, men were described as complaining that they felt uncomfortable in what was perceived as a female-dominated sphere, that they viewed facilities as overcrowded and that they felt awkward discussing health matters-especially regarding HIV—within listening distance of others. In still other instances, women resented that those who had a husband or male partner with them received faster or preferential treatment, which seemed to suggest that a man's presence lent more credence to a woman's health needs.

\section{DISCUSSION}

This study outlines community perspectives on improvements, persisting challenges and unintended negative effects throughout implementation of the SSDI-PBI programme. The findings contribute to the PBF literature in at least two ways. First, this study draws in insights from community leaders and childbearing women, perspectives that are often overlooked in academic literature related to PBF. Second, by presenting unintended effects that unfurled in the SSDI-PBI programme, the study highlights an under-researched area in the broader PBF literature and draws implementers' attention to critical issues that may constrain or undermine success in similar programs. ${ }^{24} 46$

In terms of improvements experienced during the SSDI-PBI programme, similar to other PBF studies, findings suggest that such interventions can strengthen availability of resources and the amount and depth of dialogue between health providers and their catchment communities. ${ }^{48}$ It should be noted, however, that our article reports on community perceptions and does not attempt to quantify changes in quality of care, measured in terms of either resources or patient-provider dialogue. Findings relating to medical supplies echo PBF studies in Rwanda and Burundi where women receiving prenatal care had increased chances of having their blood pressure checked, ${ }^{49}$ being given anti-tetanus vaccination ${ }^{49}$ and being treated according to the national and international guidelines. ${ }^{10} 47$ PBF studies in other settings have also described enhanced communication between providers and their catchment communities; in Rwanda and Burundi, providers worked with community health workers and community leaders to disseminate health education on the benefits of receiving maternal care in facilities, ${ }^{10}$ and in those settings utilisation rates increased which allowed facilities to attain their bonuses. ${ }^{10}$

However, success in terms of conveying the importance of care-seeking for maternal care and HIV care was accompanied by several negative, unintended effects in our study and others. ${ }^{50}{ }^{51}$ While providers worked to address quantity and quality indicators in the SSDI-PBI programme, women and community leaders reported unpleasant scenarios in the context of the programme that-paradoxically—re-affirmed community-held reservations and hesitations about accessing facility-based care. In the absence of a more rigorous prospective study focussed specifically on ANC content, it is not possible to determine if (a) the programme worsened the situation in facilities thereby sparking disappointment or (b) the programme maintained the status quo in facilities yet heightened community expectations thus inducing disappointment or (c) the programme improved the status quo in facilities yet heightened community expectations thus inducing disappointment. For example, in this study, women reported disappointment because they attended facilities earlier during antenatal period, but only had their abdomen palpated. It is likely that this approach could have been routine prior to SSDI-PBI, but the intervention-raised women's expectations of what to expect during an early ANC visit, which then led to disappointment.

The negative side effects highlighted in this study largely reflect challenges that arise when a demand for services increases without concordant increases in facility-based infrastructure, human resources and medical supplies. Several studies have demonstrated that PBF programs place formidable strain on facility-based employees in terms of workload, ${ }^{16} 245052$ which was highly salient in this study.

Beyond experiences amid overworked personnel, we also found that well-intended facets of the SSDI-PBI intervention appear to have generated unintended, negative effects even when providers were adequately responding to an incentive with the 'right' behaviour. ${ }^{53}$ The manner in which a well-intentioned indicator (here, couples testing for HIV during ANC) can spark resentment among women and intra-household marital strife generally was illuminating and echoed in related maternal health literature in Malawi ${ }^{54}$ Another study 
related to a PBF intervention in Burkina Faso also highlighted unintended negative effects; that study found that the process of community verification (a vital component of PBF requiring investigators from the community to verify that provider-reported services had been performed) inadvertently led to marital strife because respondents found it inappropriate for male verifiers to engage in private conversations with women-including those who had attended PBF clinics for maternal care. ${ }^{24}$ Equally illuminating in our study is the finding that referrals to higher-level facilities for childbirth can ultimately-and paradoxically_lead to home delivery. In this study context, facility-provided referral transport was often lacking and women did not have the means to secure their own transport. This situation speaks to a broader body of recent PBF literature that question whether such a massive, health systems overhaul is appropriate and feasible in low- and middleincome contexts. ${ }^{29} 55$

The evidence on the emergence of unintended consequences reported in this study and in other studies from sub-SaharanAfrica ${ }^{19} 2456$ partially resonates what has been documented earlier in high-income settings, such as the UK, where pay-for-performance systems have at times been observed to yield a negative impact on nonincentivised indicators. ${ }^{58-60}$ In addition to the difference that exists between pay-for-performance in high-income versus low-income system, we ought to note that the existing literature from high-income settings defines unintended consequences very specifically in relation to effects on non-incentivised clinical indicators and relies exclusively on quantitative methods. Our work instead, purposely relies on qualitative methods of data collection and analysis to allow a more open exploration of the issue at stake, looking for unintended consequences beyond clinical practice alone. In doing so, our work, similarly to the work of Turcotte-Tremblay $e t a l,{ }^{20} 24$ situates itself somewhat apart from the currently available literature on high-income settings and becomes propositive of a new and more open way of approaching the study of unintended consequences, which could find applications also in high-income settings.

As a limitation, we highlight that experiences or attitudes presented by respondents cannot be exclusively and wholly attributed to SSDI-PBI. Issues such as disrespect and abuse have emerged forcefully in recent literature within the Malawi context, ${ }^{61}$ similar settings ${ }^{62}$ and the region more generally. ${ }^{63}$ This study was cross-sectional. A longer, prospective study would more strongly allow researchers to link effects of given programme to intervention at hand. This study reports on perceptions and does not give quantifiable data in terms of changes, comparing case and control facilities. Finally, this study would have been strengthened by drawing in perspectives of providers regarding how the programme was operationalised and to what effect.

\section{CONCLUSION}

As an alternative purchasing mechanism to input-based financing, PBF programs such as SSDI-PBI hold potential, but also represent a tremendous endeavour in oftentimes weak health systems. This is especially true when PBF is not introduced within the framework of clear ministerial governance as only one out of a set of reforms and implemented in conjunction with other health financing measures targeting collection and pooling functions. This qualitative study examined the benefits, drawbacks and unintended effects of SSDI-PBI, a PBF intervention in Malawi. Our study found that community leaders and women themselves made efforts to facilitate success in reaching indicators related to skilled birth attendance and proper management of maternal risk factors across health facilities. However, these inputs were not enough to overcome formidable structural and social barriers.

\section{Author affiliations}

${ }^{1}$ University of Malawi, Kamuzu College of Nursing, Private Bag 1, Lilongwe, Malawi ${ }^{2}$ Heidelberg Institute of Global Health, University Hospital and Faculty of Medicine, Heidelberg University, Heidelberg, Baden-Württemberg, Germany

${ }^{3}$ Department of Global Health and Development, London School of Hygiene \&

Tropical Medicine, London, UK

${ }^{4}$ Department of Public health, University of Malawi, College of Medicine, Blantyre 3, Malawi

${ }^{5}$ Africa Center of Excellence in Public Health, University of Malawi, College of Medicine, Blantyre, Malawi

Twitter Shannon McMahon @shannonamcmahon

Contributors The first (C Petross) and second (S McMahon) authors contributed equally to this article. All authors contributed to the writing of this manuscript.

Funding This research project is made possible through Translating Research into Action, TRAction, which is funded by United States Agency for International Development (USAID) under cooperative agreement number No. GHSA-00-0900015-00. The project team includes the University of Heidelberg as prime recipient and the University of Malawi at the College of Medicine in Malawi as a sub-recipient. Dr McMahon is supported via an Olympia Morata Program Grant from Heidelberg University.

Competing interests Both the implementation team and the evaluation team are funded by USAID through two independent funding streams for implementation and evaluation efforts, respectively.

Patient and public involvement Patients and/or the public were not involved in the design, or conduct, or reporting or dissemination plans of this research.

Patient consent for publication Not required.

Ethics approval This study received ethical approval from the College of Medicine in Malawi (ethical approval code: P.09/15/1803) and the University of Heidelberg in Germany (ethical approval code: S-385/2015).

Provenance and peer review Not commissioned; externally peer reviewed.

Data availability statement All data relevant to the study are included in the article or uploaded as supplementary information.

Open access This is an open access article distributed in accordance with the Creative Commons Attribution Non Commercial (CC BY-NC 4.0) license, which permits others to distribute, remix, adapt, build upon this work non-commercially, and license their derivative works on different terms, provided the original work is properly cited, appropriate credit is given, any changes made indicated, and the use is non-commercial. See: http://creativecommons.org/licenses/by-nc/4.0/.

\section{REFERENCES}

1 Children St. State of the World's Mothers 2013. Westport, Connecticut; London, United Kingdom: Save the Children, 2015. 
2 Countdown. Countdown to 2015. A decade of tracking progress for maternal, newborn and child survival. Cameroon country report 2015. Available: http://www.countdown2015mnch.org/countryprofiles/cameroon

3 UN. Millennium Development Goals - Malawi 2015. Available: http:// www.mw.one.un.org/millennium-development-goals/

4 Musgrove P. Rewards for good performance or results: a short glossary. Washington, D.C: World Bank, 2011.

5 Fritsche GB, Soeters R, Meessen B. Performance-Based financing toolkit: world bank publications, 2014.

6 Meessen B, Soucat A, Sekabaraga C. Performance-Based financing: just a donor FAD or a catalyst towards comprehensive health-care reform? Bull World Health Organ 2011;89:153-6.

7 Mayaka Ma-Nitu S, Tembey L, Bigirimana E, et al. Towards constructive rethinking of PBF: perspectives of implementers in subSaharan Africa. BMJ Glob Health 2018;3:e001036.

8 Renmans D, Holvoet N, Orach CG, et al. Opening the 'black box'of performance-based financing in low-and lower middle-income countries: a review of the literature. Health Policy Plan 2016:czw045.

9 Das A, Gopalan SS, Chandramohan D. Effect of pay for performance to improve quality of maternal and child care in low- and middleincome countries: a systematic review. BMC Public Health 2016;16:321

10 Basinga P, Gertler PJ, Binagwaho A, et al. Effect on maternal and child health services in Rwanda of payment to primary healthcare providers for performance: an impact evaluation. The Lancet 2011;377:1421-8.

11 Bonfrer I, Van de Poel E, Van Doorslaer E. The effects of performance incentives on the utilization and quality of maternal and child care in Burundi. Soc Sci Med 2014;123:96-104.

12 Binyaruka P, Patouillard E, Powell-Jackson T, et al. Effect of paying for performance on utilisation, quality, and user costs of health services in Tanzania: a controlled before and after study. PLoS One 2015;10:e0135013.

13 Engineer CY, Dale E, Agarwal A, et al. Effectiveness of a pay-forperformance intervention to improve maternal and child health services in Afghanistan: a cluster-randomized trial. Int J Epidemiol 2016;45:451-9.

14 De Walque D, Robyn PJ, Saidou H, et al. Looking into the Performance-Based Financing Black Box : Evidence from an Impact Evaluation in the Health Sector in Cameroon. Policy Research Working Paper No 8162. Washington, DC: World Bank, 2017.

15 Zizien ZR, Korachais C, Compaoré P, et al. Contribution of the results-based financing strategy to improving maternal and child health indicators in Burkina Faso. Int $J$ Health Plann Manage 2019;34:111-29.

16 Kalk A, Paul FA, Grabosch E. 'Paying for performance' in Rwanda: does it pay off? Trop Med Int Health 2010;15:182-90.

17 Chimhutu V, Songstad NG, Tjomsland M, et al. The inescapable question of fairness in pay-for-performance bonus distribution: a qualitative study of health workers' experiences in Tanzania. Global Health 2016;12:77.

18 Paul E, Sossouhounto N, Eclou DS. Local stakeholders' perceptions about the introduction of performance-based financing in Benin: a case study in two health districts. Int $J$ Health Policy Manag 2014;3:207-14.

19 Ssengooba F, McPake B, Palmer N. Why performance-based contracting failed in Uganda--an "open-box" evaluation of a complex health system intervention. Soc Sci Med 2012;75:377-83.

20 Turcotte-Tremblay A-M, De Allegri M, Gali-Gali IA, et al. The unintended consequences of combining equity measures with performance-based financing in Burkina Faso. Int $J$ Equity Health 2018;17:109

21 Lohmann J, Wilhelm D, Kambala C, et al. 'The money can be a motivator, to me a little, but mostly PBF just helps me to do better in my job.' an exploration of the motivational mechanisms of performance-based financing for health workers in Malawi. Health Policy Plan 2018;33:183-91.

22 de Walque D, Gertler PJ, Bautista-Arredondo S, et al. Using provider performance incentives to increase HIV testing and counseling services in Rwanda. J Health Econ 2015;40:1-9.

23 Chimhutu V, Lindkvist I, Lange S. When incentives work too well: locally implemented pay for performance (P4P) and adverse sanctions towards home birth in Tanzania - a qualitative study. BMC Health Serv Res 2014;14:1.

24 Turcotte-Tremblay A-M, Gali-Gali IA, De Allegri M, et al. The unintended consequences of community Verifications for performance-based financing in Burkina Faso. Soc Sci Med 2017;191:226-36.

25 Wilhelm DJ, Brenner S, Muula AS, et al. A qualitative study assessing the acceptability and adoption of implementing a results based financing intervention to improve maternal and neonatal health in Malawi. BMC Health Serv Res 2016;16:398.

26 De Allegri M, Bertone MP, McMahon S, et al. Unraveling PBF effects beyond impact evaluation: results from a qualitative study in Cameroon. BMJ Glob Health 2018;3:e000693.

27 Kambala C, Lohmann J, Mazalale J, et al. Perceptions of quality across the maternal care continuum in the context of a health financing intervention: evidence from a mixed methods study in rural Malawi. BMC Health Serv Res 2017;17:392.

28 Lannes L. Improving health worker performance: the patientperspective from a PBF program in Rwanda. Soc Sci Med 2015;138:1-11.

29 Ridde V, Yaogo M, Zongo S, et al. Twelve months of implementation of health care performance-based financing in Burkina Faso: a qualitative multiple case study. Int $J$ Health Plann Manage 2018;33:e153-67.

30 Songstad NG, Lindkvist I, Moland KM, et al. Assessing performance enhancing tools: experiences with the open performance review and appraisal system (OPRAS) and expectations towards payment for performance (P4P) in the public health sector in Tanzania. Global Health 2012;8:33.

31 World Bank. The world bank aims to support Malawi's efforts toward more diversified, competitive, shock-resilient socio-economic growth. World Bank, 2019. https://www.worldbank.org/en/country/ malawi/overview

$32 \mathrm{MoH}$. Malawi Health Sector Strategic Plan 2011 - 2016. Moving towards equity and quality. Lilongwe, Malawi: MoH, 2011.

33 Mueller DH, Lungu D, Acharya A, et al. Constraints to implementing the essential health package in Malawi. PLoS One 2011;6:e20741.

34 National Statistical Office (NSO) and ICF Macro. Malawi demographic and health survey 2010. Zomba, Malawi, and Calverton, Maryland, USA: National Statistical Office (NSO) and ICF Macro, 2011.

35 NSO. Malawi mdg Endline survey 2014, 2015.

36 Brenner S, Muula AS, Robyn PJ, et al. Design of an impact evaluation using a mixed methods model - an explanatory assessment of the effects of results-based financing mechanisms on maternal healthcare services in Malawi. BMC Health Serv Res 2014:14:1-17.

37 McMahon SA, Brenner S, Lohmann J, et al. Evaluating complex health financing interventions: using mixed methods to inform further implementation of a novel PBI intervention in rural Malawi. BMC Health Serv Res 2016;16:414.

38 Ministry of Health $(\mathrm{MoH})[$ Malawi] and ICF International. Malawi service provision assessment (MspA) 2013-14. Lilongwe, Malawi, and Rockville, Maryland, USA: MoH and ICF International, 2014.

39 Assessing Quality of Care in Malawi's Support for Service Delivery and Integration Project's Performance Based Incentives Intervention. Translating research into action project. Bethesda, Maryland, U.S.A, 2015. http://www.tractionproject.org/research-areas/results-basedmanagement-incentives-quality/assessing-quality-care-malawi\% E2\% $80 \% 99$ s-support

40 Ulin PR, Robinson ET, Tolley EE. Qualitative methods in public health: a field guide for applied research. San Francisco, CA: Jossey-Bass, 2005.

41 Sofaer S. Qualitative research methods. Int J Qual Health Care 2002;14:329-36.

42 Lincoln YS, Guba EG, Pilotta JJ. Naturalistic inquiry. Newbury Park, CA: SAGE Publications, 1985: 9. 438-9.

43 McMahon SA, Winch PJ. Systematic Debriefing after qualitative encounters: an essential analysis step in applied qualitative research. BMJ Glob Health 2018;3:e000837.

44 Pope C, Ziebland S, Mays N. Qualitative research in health care. analysing qualitative data. BMJ 2000;320:114-6.

45 Bradley EH, Curry LA, Devers KJ. Qualitative data analysis for health services research: developing taxonomy, themes, and theory. Health Serv Res 2007:42:1758-72.

46 Witter S, Toonen J, Meessen B, et al. Performance-Based financing as a health system reform: mapping the key dimensions for monitoring and evaluation. BMC Health Serv Res 2013;13:367.

47 Rusa L, Ngirabega JdeD, Janssen W, et al. Performance-Based financing for better quality of services in Rwandan health centres: 3-year experience. Trop Med Int Health 2009;14:830-7.

48 Soeters R, Habineza C, Peerenboom PB. Performance-Based financing and changing the district health system: experience from Rwanda. Bull World Health Organ 2006;84:884-9.

49 Bonfrer I, Soeters R, Van de Poel E, et al. Introduction of performance-based financing in Burundi was associated with improvements in care and quality. Health Aff 2014;33:2179-87. 
50 Chimhutu V, Tjomsland M, Songstad NG, et al. Introducing payment for performance in the health sector of Tanzania- the policy process. Global Health 2015;11:1.

51 Fretheim A, Witter S, Lindahl AK, et al. Performance-Based financing in low- and middle-income countries: still more questions than answers. Bull World Health Organ 2012;90:559-A.

52 Salehi AS, Kim C, Hansen KA. A systematic review of the unintended consequences of Results-Based financing in health care. AFJPH $2017 ; 3$.

53 Turcotte-Tremblay A-M, Gali-Gali IA, Ridde V. Uncovering the unintended consequences of performance based financing in Burkina Faso. manuscript submitted for publication, 2019.

54 Mamba KC, Muula AS, Stones W. Facility-imposed barriers to early utilization of focused antenatal care services in Mangochi District, Malawi - a mixed methods assessment. BMC Pregnancy Childbirth 2017; $17: 444$.

55 Paul E, Albert L, Bisala Badibanga N'Sambuka, et al. Performancebased financing in low-income and middle-income countries: isn't it time for a rethink? BMJ Glob Health 2018;3:e000664.

56 Antony M, Bertone MP, Barthes O. Exploring implementation practices in results-based financing: the case of the verification in Benin. BMC Health Serv Res 2017;17:204.

57 Chimhutu V, Lindkvist I, Lange S. When incentives work too well: locally implemented pay for performance (P4P) and adverse sanctions towards home birth in Tanzania - a qualitative study. BMC Health Serv Res 2014;14:23.

58 Doran T, Kontopantelis E, Valderas JM, et al. Effect of financial incentives on incentivised and non-incentivised clinical activities: longitudinal analysis of data from the UK quality and outcomes framework. BMJ 2011;342:d3590.

59 Campbell SM, Reeves D, Kontopantelis E, et al. Effects of pay for performance on the quality of primary care in England. $N$ Engl $\mathrm{J} \mathrm{Med}$ 2009;361:368-78.

60 Steel N, Maisey S, Clark A, et al. Quality of clinical primary care and targeted incentive payments: an observational study. Br J Gen Pract 2007;57:449-54.

61 Sethi R, Gupta S, Oseni L, et al. The prevalence of disrespect and abuse during facility-based maternity care in Malawi: evidence from direct observations of labor and delivery. Reprod Health 2017;14:111.

62 McMahon SA, George AS, Chebet JJ, et al. Experiences of and responses to disrespectful maternity care and abuse during childbirth; a qualitative study with women and men in Morogoro region, Tanzania. BMC Pregnancy Childbirth 2014;14:268.

63 Bradley S, McCourt C, Rayment J, et al. Disrespectful intrapartum care during facility-based delivery in sub-Saharan Africa: a qualitative systematic review and thematic synthesis of women's perceptions and experiences. Soc Sci Med 2016;169:157-70. 